Article

\title{
Fabrication of Corrosion Resistance Micro-Nanostructured Superhydrophobic Anodized Aluminum in a One-Step Electrodeposition Process
}

\author{
Ying Huang, Dilip K. Sarkar * and X.-Grant Chen \\ Centre Universitaire de Recherche sur l'Aluminium (CURAL), Université du Québec à Chicoutimi, \\ 555 Boulevard de 1’Université, Chicoutimi, QC G7H 2B1, Canada; ying.huang@uqac.ca (Y.H.); \\ xgrant_chen@uqac.ca (X.-G.C.) \\ * Correspondence: dsarkar@uqac.ca; Tel.:+1-418-5455-011 (ext. 2543) \\ Academic Editor: Nong Gao \\ Received: 23 December 2015; Accepted: 22 February 2016; Published: 29 February 2016
}

\begin{abstract}
The formation of low surface energy hybrid organic-inorganic micro-nanostructured zinc stearate electrodeposit transformed the anodic aluminum oxide (AAO) surface to superhydrophobic, having a water contact angle of $160^{\circ}$. The corrosion current densities of the anodized and aluminum alloy surfaces are found to be 200 and $400 \mathrm{nA} / \mathrm{cm}^{2}$, respectively. In comparison, superhydrophobic anodic aluminum oxide (SHAAO) shows a much lower value of $88 \mathrm{nA} / \mathrm{cm}^{2}$. Similarly, the charge transfer resistance, $R_{\mathrm{ct}}$, measured by electrochemical impedance spectroscopy shows that the SHAAO substrate was found to be 200-times larger than the as-received aluminum alloy substrate. These results proved that the superhydrophobic surfaces created on the anodized surface significantly improved the corrosion resistance property of the aluminum alloy.
\end{abstract}

Keywords: superhydrophobic aluminum; corrosion; anodized aluminum oxide (AAO); organic-inorganic; micro-nanostructure; zinc stearate (ZnSA); potentiodynamic polarization; electrochemical impedance spectroscopy (EIS)

\section{Introduction}

Aluminum (Al) and its alloys are naturally-abundant engineering materials with extensive applications in daily life. In recent years, nanoporous anodic aluminum oxide (AAO) prepared by electrochemical anodization has found a multitude of applications, such as catalysis [1], drug delivery [2], biosensing [3], template synthesis [4], molecular and ion separation [5], corrosion resistance [6], and so forth. The formation of AAO on the aluminum alloy surface would act as the corrosion barrier. The formation of AAO was limited to a certain extent due to its hydrophilic behavior. Therefore, it is necessary to transform the AAO to be superhydrophobic in order to improve the corrosion resistance properties.

Superhydrophobicity, exhibiting an excellent water-repellent property, is characterized by a contact angle above $150^{\circ}$. Creating a rough surface, as well as reducing the surface energy is attributed to the modification of superhydrophobicity [7]. In the last few decades, a large effort has been devoted to the realization of superhydrophobic surfaces, due to their applications in biology [8], anti-corrosion [9-12], anti-icing [13], self-cleaning [14], etc. 
Recent publications show that the anodized surface can be made superhydrophobic by passivation with organic molecules [15-18]. In the study of Liu et al., the superhydrophobic anodized surfaces were fabricated by polypropylene (PP) coating after anodizing [17]. Li et al., used a very complex process to engineer superhydrophobic anodized aluminum alloy surfaces [16]. After anodizing with sulfuric acid, the anodized sample was firstly immersed in the mixing solution containing $\mathrm{M}\left(\mathrm{NO}_{3}\right)_{2}$ salt $(\mathrm{M}=\mathrm{Mg}, \mathrm{Co}, \mathrm{Ni}$ and $\mathrm{Zn})$ and $\mathrm{NH}_{4} \mathrm{NO}_{3}$, followed by immersion in (Heptadecafluoro-1,1,2,2-tetradecyl)trimethoxysilane $\left(n-\mathrm{CF}_{3}\left(\mathrm{CF}_{2}\right)_{7} \mathrm{CH}_{2} \mathrm{CH}_{2} \mathrm{Si}\left(\mathrm{OC}_{2} \mathrm{H}_{5}\right)_{3}\right)$. Vengatesh and Kulandainathan fabricated superhydrophobic anodic aluminum oxide (SHAAO) surfaces by passivation with organic molecules and show these surfaces having corrosion resistance properties indicated by potentiodynamic polarization [15]. Despite this, the fabrication, as well as corrosion resistance properties of the electrodeposited superhydrophobic surfaces on AAO have not been shown in the literature.

In this work, we have described the method to prepare the superhydrophobic surfaces on AAO by the electrodeposition process and describe their corrosion resistance properties, both using potentiodynamic polarization and electrochemical impedance spectroscopy (EIS).

\section{Experimental Procedure}

After pretreatment with $0.01 \mathrm{M} \mathrm{NaOH}$ at $55^{\circ} \mathrm{C}$ for $3 \mathrm{~min}$, the AA6061 aluminum alloy substrates were anodized using 3 vol. $\% \mathrm{H}_{3} \mathrm{PO}_{4}$ aqueous solution at $10{ }^{\circ} \mathrm{C}$ at $0.01 \mathrm{~A} / \mathrm{cm}^{2}$ (Ametek Sorensen DCS 100-12E, Chicoutimi, QC, Canada) for $2 \mathrm{~h}$. The superhydrophobic anodic aluminum oxide (SHAAO) surface was prepared by the electrodeposition process in an ethanolic solution containing $0.01 \mathrm{M}$ stearic acid (SA) and $0.01 \mathrm{M}$ zinc nitrate $\left(\mathrm{Zn}\left(\mathrm{NO}_{3}\right)_{2}\right)$ by applying $20 \mathrm{~V}$ (Ametek Sorensen DCS 100-12E) for $10 \mathrm{~min}$. Microstructural examination was conducted using a scanning electron microscope (SEM, JEOL JSM-6480 LV, Chicoutimi, QC, Canada). Surface roughness was measured using an optical profilometer. The X-ray diffraction (XRD) analyses of the samples were carried out using a Bruker D8 Discover system (Chicoutimi, QC, Canada). The chemical composition of the samples was analyzed by means of Fourier transform infrared spectroscopy (FTIR, Perkins Elmer Spectrum One, Chicoutimi, QC, Canada) and an energy dispersive X-ray spectrometer (EDX, JEOL JSM-6480 LV, Chicoutimi, QC, Canada). Wetting characteristics of sample surfaces were evaluated by measuring static contact angles (CA) using a first ten Angstrom contact angle goniometer at five positions on each substrate using a 10- $\mu \mathrm{L}$ deionized water drop. In the case of rolling-off surfaces, the contact angle was measured by holding the water drop between the needle and the surface, as presented in the inset image of Figure 1c. Electrochemical experiments were performed using a PGZ100 potentiostat and a $300-\mathrm{cm}^{3}$-EG \& G PAR flat cell (London Scientific, London, ON, Canada), equipped with a standard three-electrode system with an $\mathrm{Ag} / \mathrm{AgCl}$ reference electrode, a platinum (Pt) mesh as the counter electrode (CE) and the sample as the working electrode (WE). Before the test, the open circuit potential (OCP) was monitored for more than $20 \mathrm{~h}$ for stabilization by immersing the sample surface in $3 \mathrm{wt} . \% \mathrm{NaCl}$ aqueous solution. The electrochemical impedance spectroscopy (EIS) was tested in the frequency range between $10 \mathrm{MHz}$ and $100 \mathrm{kHz}$ with a sine-wave amplitude of $10 \mathrm{mV}$. For the potentiodynamic polarization experiments, the potential was scanned from $-250 \mathrm{mV}$ to $+1000 \mathrm{mV}$ with respect to the OCP voltage at a scan rate of $2 \mathrm{mV} / \mathrm{s}$. 


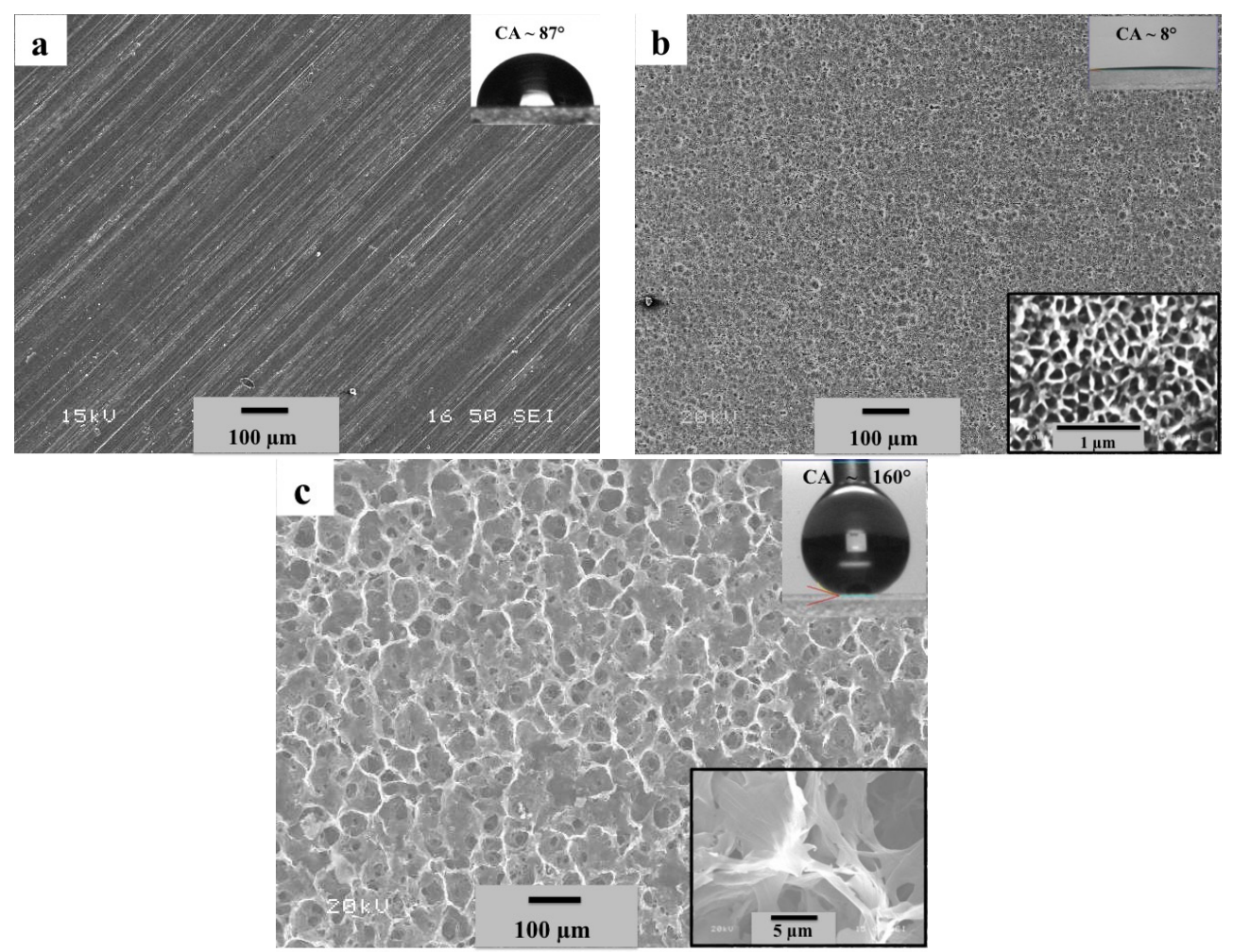

Figure 1. Secondary electron SEM micrographs showing the top surface of (a) the as-received aluminum alloy; (b) the anodized and (c) the electrodeposited anodized substrates. The inset top-right images present the water drop on the surfaces, and the bottom-right ones show magnified microstructures.

\section{Results and Discussion}

SEM images in Figure 1 reveal the evolution of the different morphologies of: (a) the as-received the aluminum alloy surface; (b) the anodized (AAO) surface; and (c) the electrodeposited hybrid organic-inorganic anodized surface using the ethanolic electrolytic solution containing stearic acid (SA) and zinc nitrate $\left(\mathrm{Zn}\left(\mathrm{NO}_{3}\right)_{2}\right)$ at $20 \mathrm{~V}$ DC. The as-received aluminum alloy surface was characterized by parallel lines resulting from the rolling process, corresponding to a surface roughness of $0.45 \pm 0.03 \mu \mathrm{m}$ and a contact angle of $87^{\circ} \pm 3^{\circ}$ (Figure 1a).

After anodizing in phosphoric acid for a duration of $2 \mathrm{~h}$, uniformly-distributed nanopores with an average diameter of approximately $100 \mathrm{~nm}$ and an inter-pore distance of $\sim 137 \mathrm{~nm}$ are observed on the surface of the anodized substrate (Figure 1b), with a roughness of $0.68 \pm 0.02 \mu \mathrm{m}$, while the contact angle was measured to be $8^{\circ} \pm 1^{\circ}$, indicating a superhydrophilic property. It is however evident from Figure $1 \mathrm{c}$ that the electrodeposition process resulted in the appearance of a porous network microstructure on the anodized substrate. This substrate was built by nanofibre clusters connected with each other, as presented in the inset of Figure 1c. It can be also observed that these micro-nanoporous structures are distributed uniformly on the anodized surface, resulting in a micro-nanorough surface having a roughness of $6.85 \pm 1.02 \mu \mathrm{m}$. Interestingly, this surface shows superhydrophobic properties with a contact angle of $160^{\circ} \pm 1^{\circ}$ having a contact angle hysteresis of $2^{\circ} \pm 1^{\circ}$.

Low angle X-ray diffraction (XRD), energy dispersive X-ray spectroscopy (EDX) and Fourier transform infrared spectroscopy (FTIR) have been carried out to determine the composition of the electrodeposited micro-nanostructure thin films on the anodized substrate, as shown in Figure 2. Figure $2 \mathrm{a}(\mathrm{a} 3)$ shows four distinct peaks at $4.2^{\circ}, 6.26^{\circ}, 8.3^{\circ}$ and $10.4^{\circ}$, which correspond to zinc stearate $\left(\left(\mathrm{CH}_{3}\left(\mathrm{CH}_{2}\right)_{16} \mathrm{COO}\right)_{2} \mathrm{Zn}\right)$ (abbreviated as $\mathrm{ZnSA}$, ). The possible mechanism of the formation of $\mathrm{ZnSA}$ has been presented as follows: 

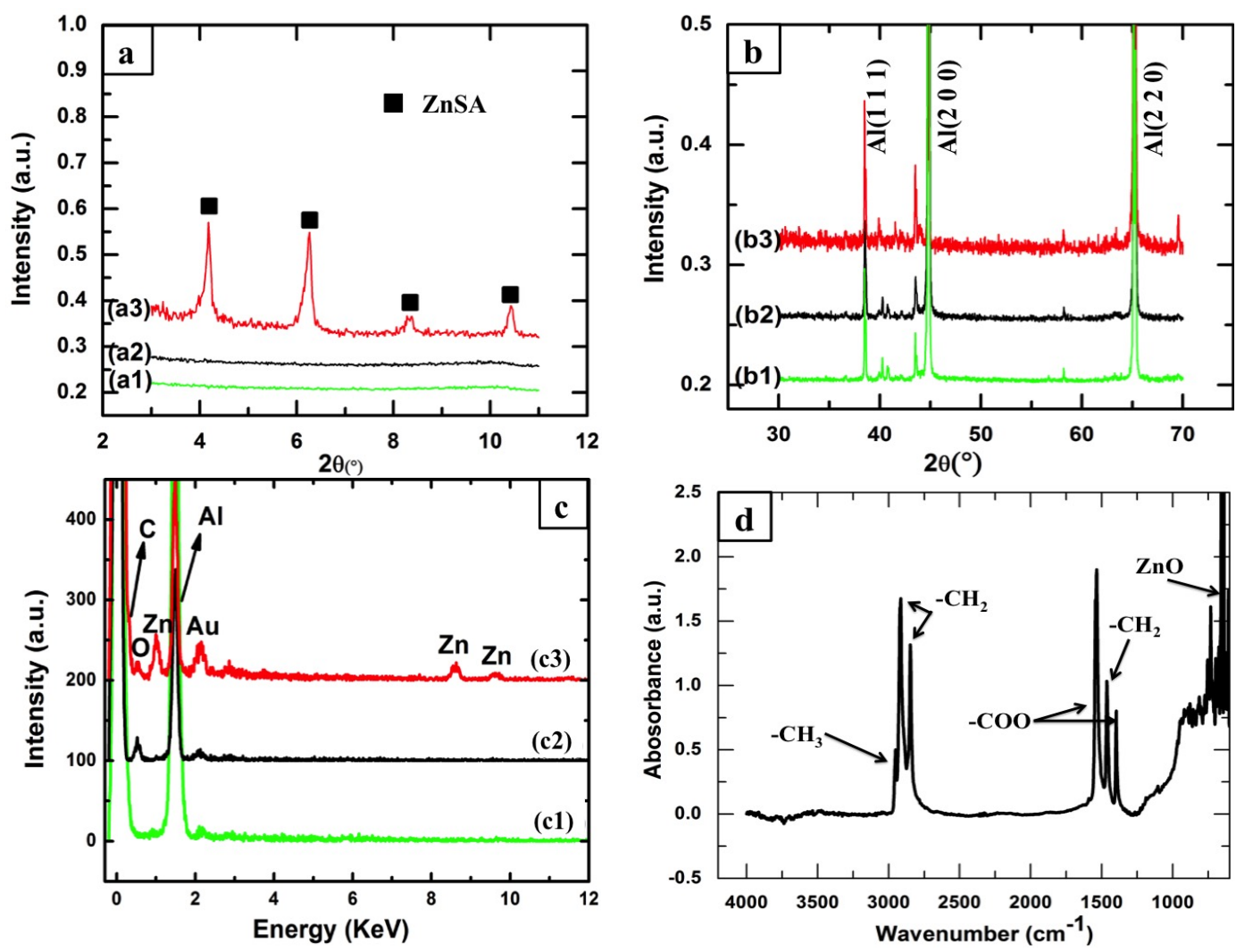

Figure 2. (a) Low angle XRD patterns of (a1) as-received aluminum alloy, (a2) AAO, (a3) electrodeposited anodized substrate; (b) high angle XRD patterns of (b1) as-received aluminum alloy, (b2) AAO and (b3) electrodeposited anodized substrate; (c) EDX spectra of (c1) the as-received aluminum alloy, (c2) anodized and (c3) electrodeposited anodized substrate (ZnSA = zinc stearate);

(d) FTIR spectrum of the electrodeposited anodized substrate.

$$
2 \mathrm{CH}_{3}\left(\mathrm{CH}_{2}\right)_{16} \mathrm{COOH}+\mathrm{Zn}^{2+} \stackrel{20 \mathrm{~V}}{\rightarrow}\left(\mathrm{CH}_{3}\left(\mathrm{CH}_{2}\right)_{16} \mathrm{COO}\right)_{2} \mathrm{Zn}+2 \mathrm{H}^{+}
$$

This reaction mechanism is very similar to that mentioned by Liu et al. for the electrodeposition of cerium myristate by electrodeposition on magnesium substrates to obtain superhydrophobicity [19]. When the DC voltage was applied on the electrodes, the $\mathrm{Zn}^{2+}$ ions close to the cathodic electrode reacted with SA, forming ZnSA and $\mathrm{H}^{+}$ions, as presented in Equation (1). Meanwhile, some of the $\mathrm{H}^{+}$ions obtained an electron and formed $\mathrm{H}_{2}$ gas. It is noted that the as-received aluminum alloy and anodized substrates of Figure $2 \mathrm{a}(\mathrm{a} 1, \mathrm{a} 2)$ do not show any characteristic peaks. Furthermore, in Figure $2 \mathrm{~b}$, it shows the peaks at $38.47^{\circ}, 44.72^{\circ}$ and $65.1^{\circ}$, respectively, which are in good agreement with the characteristic peaks of $\mathrm{Al}(111)$, (200) and (220). This arises from the substrate of the aluminum alloy.

EDX analysis (Figure 2c) revealed that the chemical composition of the anodized surface consisted of $\mathrm{O}$ and $\mathrm{Al}$, resulting from the formation of aluminum oxide $\left(\mathrm{Al}_{2} \mathrm{O}_{3}\right)$, whereas only the $\mathrm{Al}$ peak was seen in the spectrum of the as-received aluminum alloy surface. However, $\mathrm{C}, \mathrm{Zn}, \mathrm{O}$ and $\mathrm{Al}$ are observed in the spectrum of electrodeposited anodized surface, confirming the formation of ZnSA complementary with the XRD pattern of the electrodeposited anodized substrate. It is worth mentioning that the Au peaks appearing in Figure $2 \mathrm{c}$ are due to the thin layer of gold on the electrodeposited thin films for improving the resolution by eliminating the charging effect of non-conducting samples during EDX analyses.

In the FTIR spectrum of the electrodeposited hybrid organic-inorganic anodized substrate (Figure 2d), the appearance of the $-\mathrm{CH}$ group $\left(-\mathrm{CH}_{3}\right.$ at $2962 \mathrm{~cm}^{-1}$, as well as $-\mathrm{CH}_{2}$ at $1459 \mathrm{~cm}^{-1}$, $2850 \mathrm{~cm}^{-1}$ and $2919 \mathrm{~cm}^{-1}$ ), as well as -COO at 1395 and $1550 \mathrm{~cm}^{-1}$ indicated the formation of ZnSA 
on the surface [20], which is in good agreement with the XRD and EDX results. These results support the formation of low surface energy methylated $\left(-\mathrm{CH}_{3}\right.$ and $\left.-\mathrm{CH}_{2}\right)$ components on the electrodeposited anodized surface and make it superhydrophobic. In addition, the $\mathrm{ZnO}$ peaks at $560 \mathrm{~cm}^{-1}$ may come from the bonding of $-\mathrm{COOZn}$, which further verifies the reaction production of ZnSA formed on the modified surface in a one-step electrodeposition process.

Figure 3 illustrates the variation of open circuit potential (OCP) on the superhydrophobic AAO (SHAAO) surface. The OCP value shifted from -177 to $-708 \mathrm{mV}$ with an average of $-281 \pm 87 \mathrm{mV}$ into a 5 -h immersion time in the salt solution. It is quite unstable during this period. From 5 to $16 \mathrm{~h}$ of immersion time, the OCP value varied from -533 to $-686 \mathrm{mV}$ with an average of $-610 \pm 26.8 \mathrm{mV}$. With the prolongation of immersion time to $20 \mathrm{~h}$, the OCP value varied from -708 to $-730 \mathrm{mV}$, with an average of $-717 \pm 2.8 \mathrm{mV}$. It can be seen that the fluctuation of OCP voltage reduces with time and stabilized nearly after $20 \mathrm{~h}$. In contrast, the surface of the aluminum alloy substrate gets stabilized within $30 \mathrm{~min}$ of immersion time in the salt solution. The OCP fluctuations of the SHAAO substrate may be due to the poor wetting, as well as protective properties of the SHAAO surface with the salt solution. Therefore, the EIS and polarization experiments were performed after $20 \mathrm{~h}$ of immersion of the superhydrophobic surface in the salt solution while monitoring the OCP continuously.

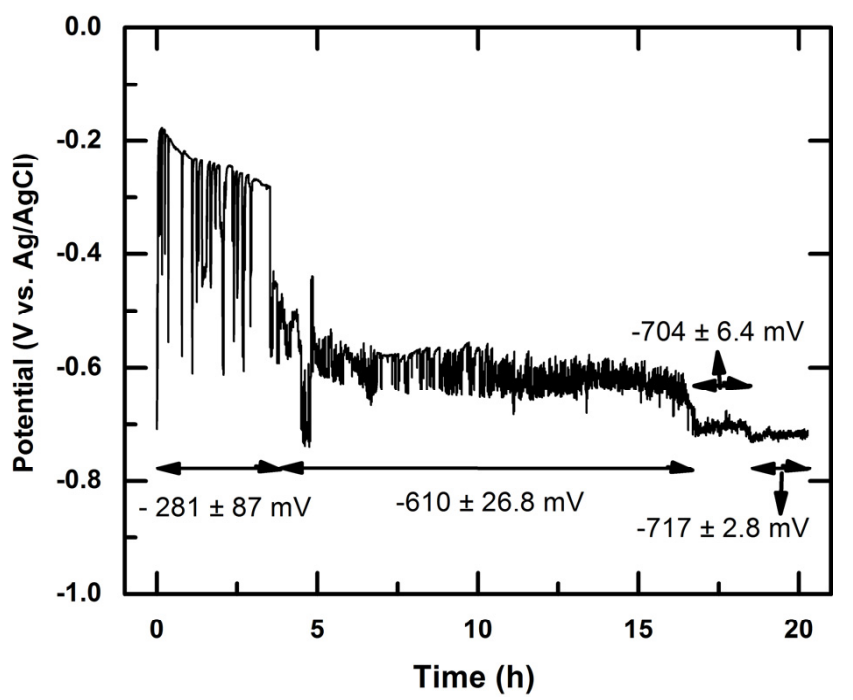

Figure 3. The variation of open circuit potential (OCP) with time on the superhydrophobic AAO (SHAAO) surface.

To evaluate the corrosion resistance performance of the fabricated anodized and SHAAO substrates, potentiodynamic polarization and electrochemical impedance spectroscopy (EIS) tests were carried out. Figure 4a shows the polarization curves of the as-received aluminum alloy, anodized and SHAAO substrates, respectively. The as-received aluminum alloy substrate exhibited a corrosion current density $\left(I_{\text {corr }}\right)$ of $400 \mathrm{nA} / \mathrm{cm}^{2}$ and a polarization resistance $\left(R_{\mathrm{p}}\right)$ of $50 \mathrm{k} \Omega \cdot \mathrm{cm}^{2}$. The $R_{\mathrm{p}}$ value was calculated by the Stern-Geary equation, as shown in Equation (2). 

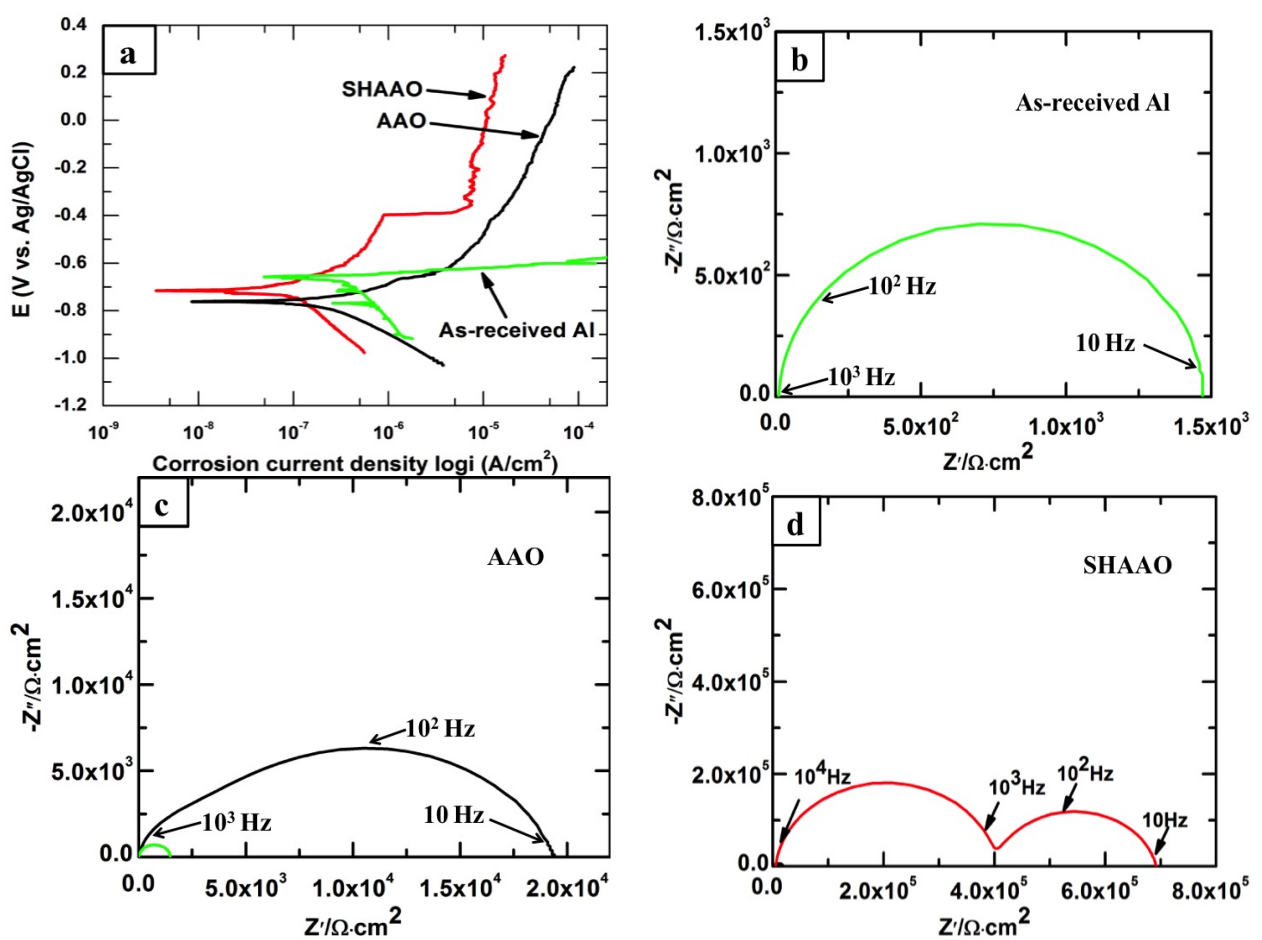

Figure 4. (a) Polarization curves of the as-received aluminum alloy, AAO and SHAAO substrates in 3 wt. \% NaCl corrosive solution; (b-d) the Nyquist plots of (b) as-received aluminum alloy; (c) AAO (as-received aluminum alloy (a small semicircle in green close to the origin) also shown for comparison) and (d) SHAAO substrate (as-received aluminum alloy and AAO also shown inside for comparison, very small semicircle, nearly visible, close to the origin).

$$
R \mathrm{p}=\frac{\beta_{\mathrm{a}} \beta_{\mathrm{c}}}{2.3 I_{\mathrm{corr}}\left(\beta_{\mathrm{a}}+\beta_{\mathrm{c}}\right)}
$$

When the aluminum alloy substrate was anodized, the $I_{\text {corr }}$ was reduced to $200 \mathrm{nA} / \mathrm{cm}^{2}$, and $R_{\mathrm{p}}$ increased to $87 \mathrm{k} \Omega \cdot \mathrm{cm}^{2}$, indicating an improved corrosion resistance compared to the as-received substrate. This was due to a barrier layer formed on the anodized surface. On the other hand, the $I_{\text {corr }}$ of the hybrid organic-inorganic SHAAO substrate decreased remarkably to $88 \mathrm{nA} / \mathrm{cm}^{2}$, while the $R_{\mathrm{p}}$ increased up to $441 \mathrm{k} \Omega \cdot \mathrm{cm}^{2}$. This shows an even better anti-corrosion performance of the SHAAO substrate relative to the anodized substrate, likely attributed to the superhydrophobic ZnSA coating formed on the surface. It is noticed that the current density of the SHAAO substrate was increased sharply at around $-0.4 \mathrm{~V}$ vs. $\mathrm{Ag} / \mathrm{AgCl}$, which might have been related to the dissolution of the superhydrophobic film with the prolongation of corrosion time (more than $20 \mathrm{~h}$ ). It is also found that the current density of the SHAAO substrate at $-0.4 \mathrm{~V}$ to $0.2 \mathrm{~V}$ vs. $\mathrm{Ag} / \mathrm{AgCl}$ was parallel to, but smaller than, that of the anodized substrate. This might be due to the superhydrophobic material ZnSA filling the anodized pore structure. As a result, the SHAAO substrate after dissolution of the surface material still presents a good corrosion resistance property.

The $I_{\text {corr }}$ of the electrodeposited cerium stearate superhydrophobic $\mathrm{Mg}$ surfaces was reported to be $142 \mathrm{nA} / \mathrm{cm}^{2}$ with a 30-min immersion to perform OCP [19]. Experiments performed by Vengatesh and Kulandainathan with a 30-min immersion before polarization show that the corrosion current varies between 2 and $1050 \mathrm{nA} / \mathrm{cm}^{2}$, depending on the passivated molecules [15]. Moreover, in the study of He et al., a 1-h immersion time is used for the stabilization [21]. In our experiment, the samples were exposed to $\mathrm{NaCl}$ solution for $20 \mathrm{~h}$ to stabilize under OCP. This indicates that our superhydrophobic film displays a better stability and durability in the corrosion test as compared to the reported values in the literature. 
Nyquist plots of the as-received aluminum alloy, anodized and hybrid organic-inorganic SHAAO substrate are presented in Figure $4 \mathrm{~b}-\mathrm{d}$. It is well known that $R_{\mathrm{ct}}$ is the charge transfer resistance, describing the difficulty of the corrosion occurring on the substrate. $R_{\mathrm{ct}}$ of anodized substrate is found to be $14 \mathrm{k} \Omega \cdot \mathrm{cm}^{2}$ in Figure $4 \mathrm{c}$, which is about 10-times higher than that of the as-received aluminum alloy substrate $\left(1.5 \mathrm{k} \Omega \cdot \mathrm{cm}^{2}\right)$ in Figure $4 \mathrm{~b}$. However, the corrosion protection of the SHAAO substrate is the combined effect of $R_{\mathrm{ct}}$ of $284 \mathrm{k} \Omega \cdot \mathrm{cm}^{2}$ (semicircle at low frequency) along with the resistance of the superhydrophobic films of $405 \mathrm{k} \Omega \cdot \mathrm{cm}^{2}$ (semicircle at high frequency) in Figure $4 \mathrm{~d}$. This indicates a significant enhancement of corrosion resistance, which is complementary to the result from the polarization curves, where the polarization resistance of SHAAO is higher than the anodized substrate, as well as for the $\mathrm{Al}$ substrate.

In the study of Liu et al. [19], the $R_{\mathrm{ct}}$ of the superhydrophobic magnesium substrate covered with cerium myristate was found to be $13 \mathrm{k} \Omega$, which is comparable to our anodized substrate, but much smaller than our zinc stearate-covered SHAAO substrate [19].

\section{Conclusions}

A superhydrophobic anodic aluminum oxide (SHAAO) surface was prepared by the electrodeposition process using the ethanolic solution of stearic acid (SA) mixed with zinc nitrate $\left(\mathrm{Zn}\left(\mathrm{NO}_{3}\right)_{2}\right)$ at a constant voltage of $20 \mathrm{~V}$. The hybrid organic-inorganic SHAAO surface having a micro-nanoporous structure of low surface energy zinc stearate (ZnSA) exhibits a water contact angle (CA) of $160^{\circ} \pm 1^{\circ}$. The SHAAO substrate has a polarization resistance $\left(R_{\mathrm{p}}\right)$ and charge transfer resistance $\left(R_{\mathrm{ct}}\right)$ of 441 and $284 \mathrm{k} \Omega \cdot \mathrm{cm}^{2}$, respectively, much higher than that of the as-received aluminum $\left(R_{\mathrm{p}}\right.$ of $50 \mathrm{k} \Omega \cdot \mathrm{cm}^{2}$ and $R_{\mathrm{ct}}$ of $\left.1.46 \mathrm{k} \Omega \cdot \mathrm{cm}^{2}\right)$ and anodized aluminum substrate $\left(R_{\mathrm{p}}\right.$ of $87 \mathrm{k} \Omega \cdot \mathrm{cm}^{2}$ and $R_{\mathrm{ct}}$ of $14 \mathrm{k} \Omega \cdot \mathrm{cm}^{2}$ ) in the corrosion. This indicates that the SHAAO substrate displays a much better corrosion resistance property as compared to the as-received aluminum alloy substrate, as well as the anodic aluminum oxide (AAO) substrate.

Acknowledgments: We acknowledge the financial support provided by the Natural Science and Engineering Research Council of Canada (NSERC) and the Aluminium Research Centre-REGAL.

Author Contributions: Ying Huang performed experiments, analysed data and wrote the draft of manuscript; D.K. Sarkar and X.-Grant Chen supervised the works. All authors took part in the discussion, the preparation and revision of the manuscript.

Conflicts of Interest: The authors declare no conflict of interest.

\section{Abbreviations}

$\begin{array}{ll}\text { AAO } & \text { Anodized aluminum oxide } \\ \text { SHAAO } & \text { Superhydrophobic anodized aluminum oxide } \\ \text { SA } & \text { Stearic acid } \\ \text { ZnSA } & \text { Zinc stearate } \\ \text { EIS } & \text { Electrochemical impedance spectroscopy } \\ \text { OCP } & \text { Open circuit potential } \\ \text { CA } & \text { Contact angle } \\ \text { SEM } & \text { Scanning electron microscope } \\ \text { XRD } & \text { X-ray diffraction } \\ \text { FTIR } & \text { Fourier transform infrared spectroscopy } \\ \text { EDX } & \text { Energy dispersive X-ray spectrometer }\end{array}$

\section{References}

1. Dotzauer, D.M.; Dai, J.; Sun, L.; Bruening, M.L. Catalytic membranes prepared using layer-by-layer adsorption of polyelectrolyte/metal nanoparticle films in porous supports. Nano Lett. 2006, 6, 2268-2272. [CrossRef] [PubMed] 
2. Simovic, S.; Losic, D.; Vasilev, K. Controlled drug release from porous materials by plasma polymer deposition. Chem. Commun. 2010, 46, 1317-1319. [CrossRef] [PubMed]

3. Wang, M.; Meng, G.; Huang, Q.; Xu, Q.; Chu, Z.; Zhu, C. FITC-modified PPy nanotubes embedded in nanoporous AAO membrane can detect trace PCB20 via fluorescence ratiometric measurement. Chem. Commun. 2011, 47, 3808-3810. [CrossRef] [PubMed]

4. Liu, Y.; Goebl, J.; Yin, Y. Templated synthesis of nanostructured materials. Chem. Soc. Rev. 2013, 42, 2610-2653. [CrossRef] [PubMed]

5. Jani, A.M.M.; Anglin, E.J.; McInnes, S.J.P.; Losic, D.; Shapter, J.G.; Voelcker, N.H. Nanoporous anodic aluminium oxide membranes with layered surface chemistry. Chem. Commun. 2009, 21, 3062-3064. [CrossRef] [PubMed]

6. Bouchama, L.; Azzouz, N.; Boukmouche, N.; Chopart, J.P.; Daltin, A.L.; Bouznit, Y. Enhancing aluminum corrosion resistance by two-step anodizing process. Surf. Coat. Technol. 2013, 235, 676-684. [CrossRef]

7. Huang, Y.; Sarkar, D.K.; Chen, X.-G. A one-step process to engineer superhydrophobic copper surfaces. Mater. Lett. 2010, 64, 2722-2724. [CrossRef]

8. Ciasca, G.; Papi, M.; Chiarpotto, M.; de Ninno, A.; Giovine, E.; Campi, G.; Gerardino, A.; de Spirito, M.; Businaro, L. Controlling the cassie-to-wenzel transition: An easy route towards the realization of tridimensional arrays of biological objects. Nano-Micro Lett. 2014, 6, 280-286. [CrossRef]

9. Zhang, F.; Chen, S.; Dong, L.; Lei, Y.; Liu, T.; Yin, Y. Preparation of superhydrophobic films on titanium as effective corrosion barriers. Appl. Surf. Sci. 2011, 257, 2587-2591. [CrossRef]

10. Yin, B.; Fang, L.; Tang, A.-Q.; Huang, Q.-L.; Hu, J.; Mao, J.-H.; Bai, G.; Bai, H. Novel strategy in increasing stability and corrosion resistance for super-hydrophobic coating on aluminum alloy surfaces. Appl. Surf. Sci. 2011, 258, 580-585. [CrossRef]

11. Huang, Y.; Sarkar, D.K.; Chen, X.-G. Superhydrophobic aluminum alloy surfaces prepared by chemical etching process and their corrosion resistance properties. Appl. Surf. Sci. 2015, 356, 1012-1024. [CrossRef]

12. Huang, Y.; Sarkar, D.K.; Gallant, D.; Chen, X.-G. Corrosion resistance properties of superhydrophobic copper surfaces fabricated by one-step electrochemical modification process. Appl. Surf. Sci. 2013, 282, 689-694. [CrossRef]

13. Zuo, Z.; Liao, R.; Guo, C.; Yuan, Y.; Zhao, X.; Zhuang, A.; Zhang, Y. Fabrication and anti-icing property of coral-like superhydrophobic aluminum surface. Appl. Surf. Sci. 2015, 331, 132-139. [CrossRef]

14. Watson, G.S.; Green, D.W.; Schwarzkopf, L.; Li, X.; Cribb, B.W.; Myhra, S.; Watson, J.A. A gecko skin micro/nano structure-A low adhesion, superhydrophobic, anti-wetting, self-cleaning, biocompatible, antibacterial surface. Acta Biomater. 2015, 21, 109-122. [CrossRef] [PubMed]

15. Vengatesh, P.; Kulandainathan, M.A. Hierarchically ordered self-lubricating superhydrophobic anodized aluminum surfaces with enhanced corrosion resistance. ACS Appl. Mater. Interfaces 2015, 7, 1516-1526. [CrossRef] [PubMed]

16. Li, Y.; Li, S.; Zhang, Y.; Yu, M.; Liu, J. Fabrication of superhydrophobic layered double hydroxides films with different metal cations on anodized aluminum 2198 alloy. Mater. Lett. 2015, 142, 137-140. [CrossRef]

17. Liu, W.; Luo, Y.; Sun, L.; Wu, R.; Jiang, H.; Liu, Y. Fabrication of the superhydrophobic surface on aluminum alloy by anodizing and polymeric coating. Appl. Surf. Sci. 2013, 264, 872-878. [CrossRef]

18. Fujii, T.; Aoki, Y.; Habazaki, H. Superhydrophobic hierarchical surfaces fabricated by anodizing of oblique angle deposited Al-Nb alloy columnar films. Appl. Surf. Sci. 2011, 257, 8282-8288. [CrossRef]

19. Liu, Q.; Kang, Z. One-step electrodeposition process to fabricate superhydrophobic surface with improved anticorrosion property on magnesium alloy. Mater. Lett. 2014, 137, 210-213. [CrossRef]

20. Huang, Y.; Sarkar, D.K.; Chen, X.-G. Superhydrophobic nanostructured zno thin films on aluminum alloy substrates by electrophoretic deposition process. Appl. Surf. Sci. 2015, 327, 327-334. [CrossRef]

21. He, T.; Wang, Y.; Zhang, Y.; Lv, Q.; Xu, T.; Liu, T. Super-hydrophobic surface treatment as corrosion protection for aluminum in seawater. Corros. Sci. 2009, 51, 1757-1761. [CrossRef]

(c) 2016 by the authors; licensee MDPI, Basel, Switzerland. This article is an open access article distributed under the terms and conditions of the Creative Commons by Attribution (CC-BY) license (http://creativecommons.org/licenses/by/4.0/). 